\title{
Rapidly Progressive Pansclerotic Morphea Associated With Raynaud Phenomenon
}

\author{
Rkiouak Adil, Ph.D. ${ }^{1}$, El Kassimi Ilyas, M.D. ${ }^{1}$, Sahel Nawal, M.D. ${ }^{1}$, Zaizaa Meryem, M.D. ${ }^{1}$, \\ Mohamed Tbouda, M.D. ${ }^{2}$, Sekkach Youssef, Ph.D. ${ }^{1}$ \\ Departments of ${ }^{1}$ Internal Medicine A and ${ }^{2}$ Anatomopathology, Mohammed V Military Hospital, Medical School of Rabat, Rabat, Morocco
}

A 52-years-old Moroccan patient with no history of autoimmune disease, presented to our department in June 2019 for scleroderma skin lesions. The lesions, initially localised, extended in few months to the entire integument, causing painful contractures, tendon retractions and joint stiffness.

On examination, the skin was sclerotic (Figure 1) and she developed numerous hypopigmented atrophic sclerotic plaques with brownish cupboards, and a "lilac ring" border type diffusely on the trunk, and extremities clin- ically consistent with pansclerotic morphea. There was sparing of the face and feet, and presence of Raynaud phenomenon (Figure 2) with no symptoms of visceral involvement.

The chest X-ray and the capillaroscopy were completely normal.

The immunological assessment was negative (negative anti-nuclear antibodies, anti-Scl70 and anti-DNA). Magnetic resonance imaging of the left thigh showed hypodermis infiltration over the entire fascia thickness without ab-
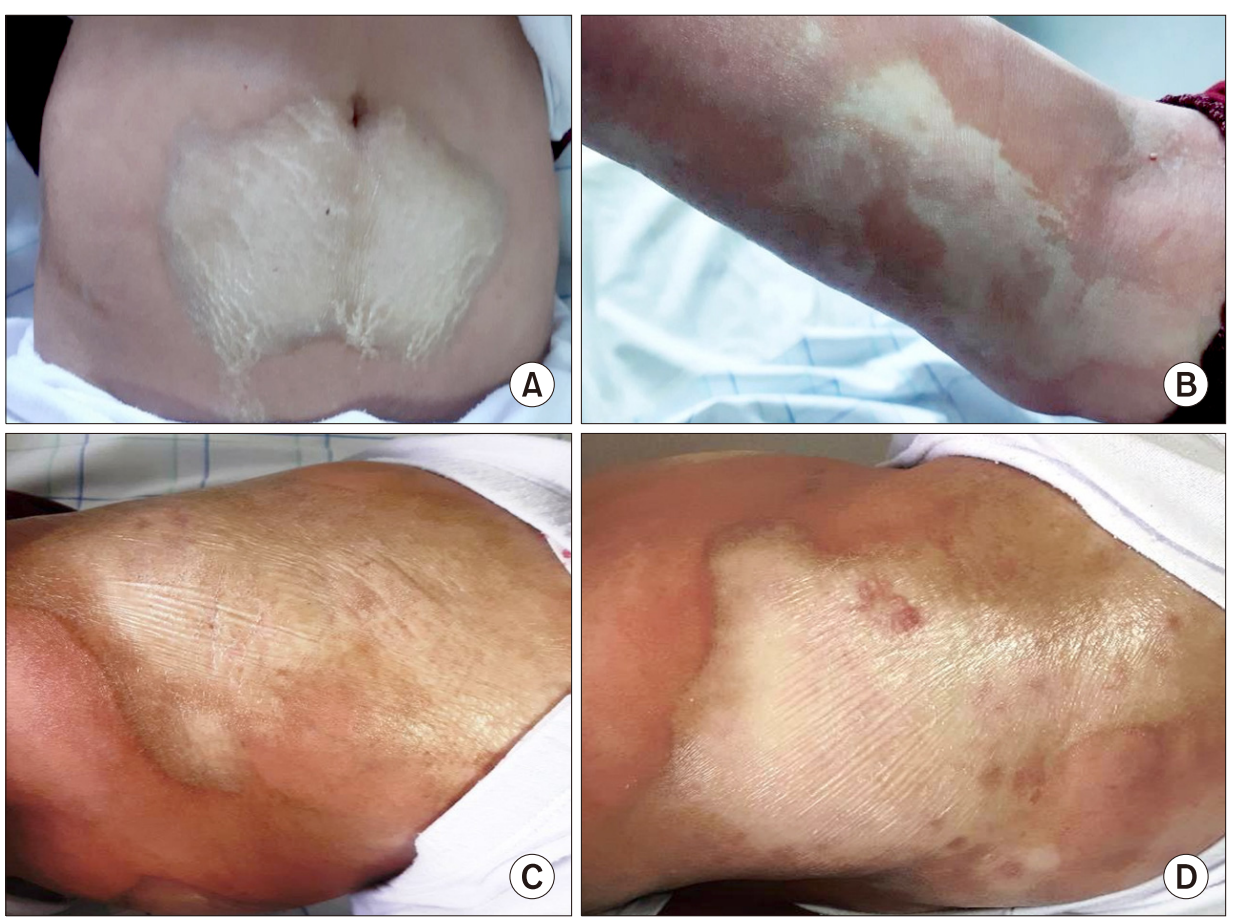

Figure 1. (A) Extended plates at all trunk with sclerotic skin. (B) Atrophy and contractures in the arm and the forearm with a sclerotic hypopigmented. (C, D) Morpheus plaque with an ivory-colored center of the buttocks and thighs (after receiving the patient's consent form about publishing all photographic materials).

Received : January 21, 2020, Revised : (1st) February 26, 2020, (2nd) March 13, 2020, Accepted : March 14, 2020

Corresponding to : Rkiouak Adil (iDhttp://orcid.org/0000-0003-0261-5044

Department of Internal Medicine A, Mohammed V Military Hospital Medical School of Rabat, Hay Riad, Rabat 10100, Morocco. E-mail : arkiouak@yahoo.fr

Copyright (c) 2020 by The Korean College of Rheumatology. All rights reserved.

This is an Open Access article, which permits unrestricted non-commerical use, distribution, and reproduction in any medium, provided the original work is properly cited. 

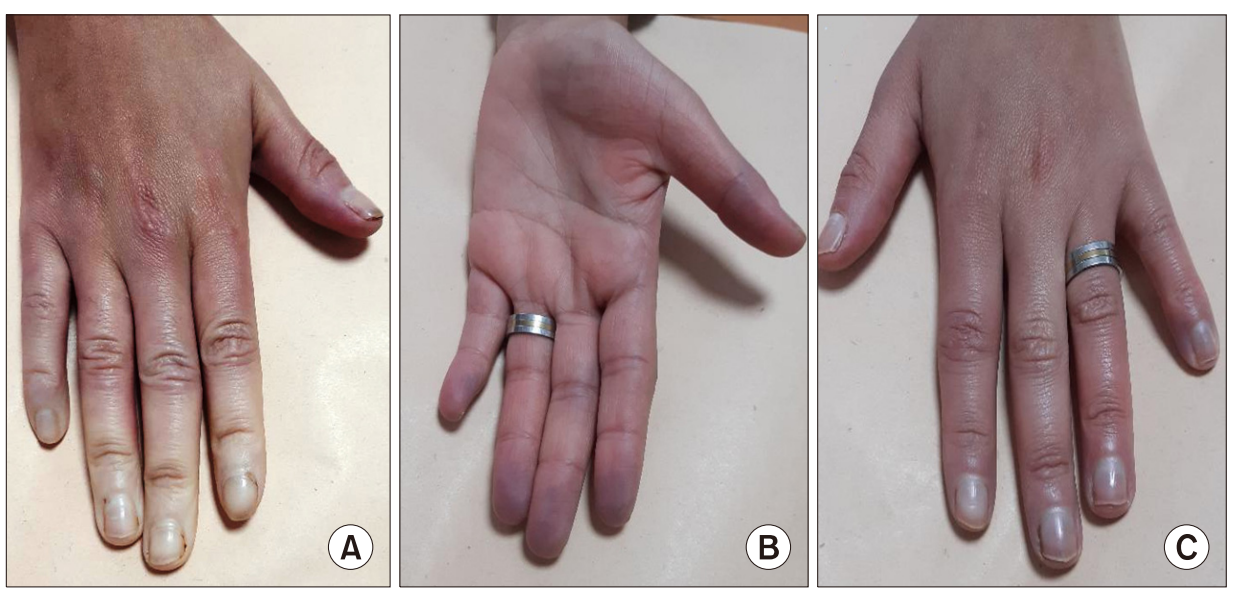

Figure 2. Raynaud phenomenon: episodic, symmetric, acral vasospasm, Note the discoloration of the fingers, Pallor: due to vasoconstriction of precapillary muscular arterioles (A), cyanosis: due to venous pooling and deoxygenation of venous blood (B), erythema: reactive hyperemia $(\mathrm{C})$.
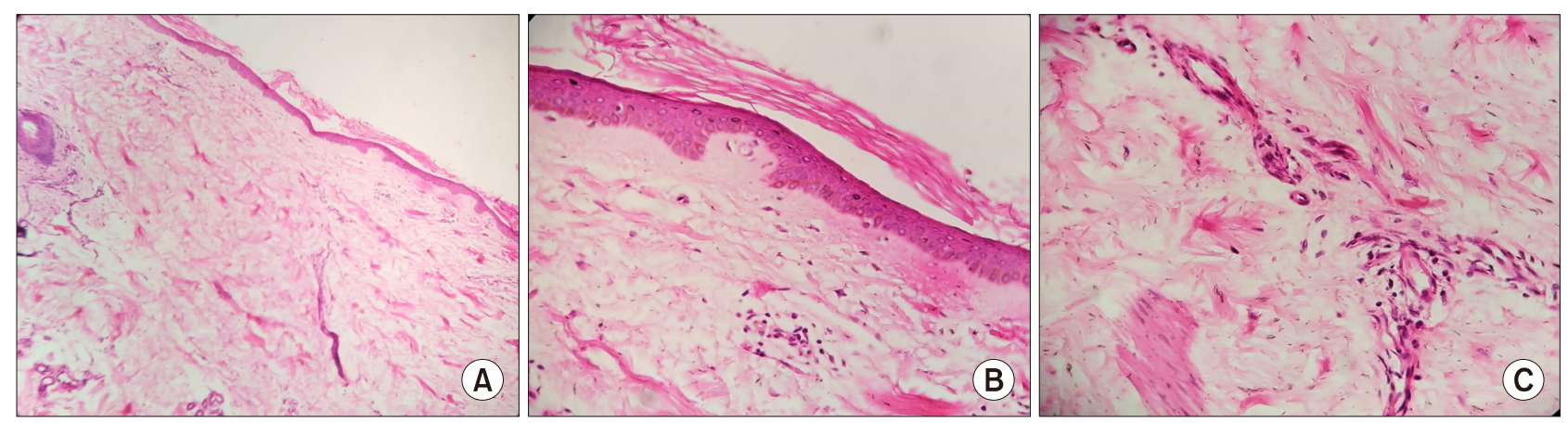

Figure 3. Skin biopsy showing. (A) Marked thickening of the dermis with sclerotic bands of collagen extending into the subcutaneous fat, atrophic epidermis topped by parakeratotic hyperkeratosis $(H \& E, \times 100)$. (B) Atrophy of epidermis with fibrosis extending from the dermis to the hypodermis $(\mathrm{H} \& \mathrm{E}, \times 200)$. (C) Fibrous dermis with a few gaping vessels surrounded of a mononuclear inflammatory infiltration $(\mathrm{H} \& \mathrm{E}, \times 200)$.

normal signal from the muscles. The anatomopathological examination of the skin (Figure 3) and muscle biopsies showed a fibrosis extending from the dermis to the hypodermis and the fascia. However, no improvement was noticed after the administration of: subcutaneous methotrexate ( $15 \mathrm{mg} /$ week) combined with oral corticosteroid therapy $(0.5 \mathrm{mg} / \mathrm{kg} /$ day of prednisone) for three months. Over the six months, she continued to develop new plaques with worsening fibrosis despite the addition of pulse methylprednisolone and mycophenolate mofetil to the methotrexate treatment regimen.

Several studies have been published, notably that of Laxer and Zulian [1], which has five subtypes: in plates, linear, generalized, mixed and pansclerotic. The pansclerotic morphea is an exceptional and extremely severe form of cutaneous scleroderma, its occurrence is exceptional. It is individualized by rapidly progressive damage, extensive lesions, painful contractures and a limitation of joints mobility. It should be distinguished from systemic scleroderma, which begins with acrosclerosis, the pres- ence of megacapillaries and visceral involvement. The presence of Raynaud's phenomenon in our case is not classically described in the Pansclerotic morphea.

Kim et al. [2], in a retrospective study, underline that the pansclerotic form has a whole different entity from other sybtypes. For example many clinical cases report increased risk of squamous cell carcinoma with pansclerotic morphea [3]. Moreover, the treatment remains disappointing to this day with unsatisfactory treatments results with methotrexate and corticosteroids [4].

Pansclerotic morphea is extremely rare and has a severe, progressive.

Currently, no therapeutic modality has been proved to be effective. Tocilizumab may be effective for treatment-refractory morphea [5].

\section{CONFLICT OF INTEREST}

No potential conflict of interest relevant to this article was reported. 


\section{AUTHOR CONTRIBUTIONS}

R.A. appointed topic, wrote and revised the manuscript. M.T. was responsible for the analysis and the interpretation of the pathology. E.K.I. determined and adjusted the topic, concept and drafting of the manuscript. S.N. and Z.M. analysis and interpretation of data. S.Y. involved in critically revising the final preparation.

\section{REFERENCES}

1. Laxer RM, Zulian F. Localized scleroderma. Curr Opin Rheumatol 2006;18:606-13.

2. Kim A, Marinkovich N, Vasquez R, Jacobe HT. Clinical features of patients with morphea and the pansclerotic subtype: a cross-sectional study from the morphea in adults and children cohort. J Rheumatol 2014;41:106-12.

3. Wollina U. Increased risk of cancer in patients with scleroderma: no risk in patients with morphoea? Ann Rheum Dis 2004;63:611-2.

4. Hardy J, Audouin-Pajot C, Abid A, Chiotasso D, Coustets B, Suc A, et al. [Pansclerotic morphea with a rapidly fatal outcome in an 11-year-old girl]. Ann Dermatol Venereol 2016; 143:836-40. French.

5. Zhang A, Nocton J, Chiu Y. A case of pansclerotic morphea treated with tocilizumab. JAMA Dermatol 2019;155:388-9. 